\title{
Concentration Dependent Single Chain Properties of Poly(sodium 4-styrenesulfonate) Subjected to Aromatic Interactions with Chlorpheniramine Maleate Studied by Diafiltration and Synchrotron-SAXS
}

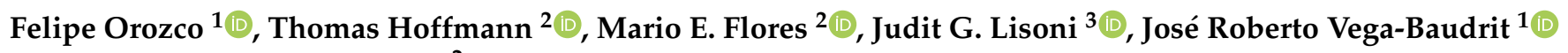 \\ and Ignacio Moreno-Villoslada ${ }^{2, *}$ \\ 1 Laboratorio Nacional de Nanotecnología LANOTEC-CENAT, Centro Nacional de Alta Tecnología, Pavas, \\ San José 1174-1200, Costa Rica; f.orozco.gutierrez@rug.nl (F.O.); jvegab@gmail.com (J.R.V.-B.) \\ 2 Laboratorio de Polímeros, Instituto de Ciencias Químicas, Facultad de Ciencias, Universidad Austral de \\ Chile, Casilla 567, Valdivia 5090000, Chile; thomas.hoffmann@uach.cl (T.H.); mario.flores@uach.cl (M.E.F.) \\ 3 Facultad de Ciencias, Instituto de Ciencias Físicas y Matemáticas, Universidad Austral de Chile, \\ Valdivia 5090000, Chile; judit.lisoni@uach.cl \\ * Correspondence: imorenovilloslada@uach.cl
}

check for updates

Citation: Orozco, F.; Hoffmann, T.;

Flores, M.E.; Lisoni, J.G.;

Vega-Baudrit, J.R.; Moreno-Villoslada,

I. Concentration Dependent Single

Chain Properties of Poly(sodium

4-styrenesulfonate) Subjected to

Aromatic Interactions with

Chlorpheniramine Maleate Studied

by Diafiltration and

Synchrotron-SAXS. Polymers 2021, 13,

3563. https://doi.org/10.3390/

polym13203563

Academic Editor: Bramasta Nugraha

Received: 31 August 2021

Accepted: 1 October 2021

Published: 15 October 2021

Publisher's Note: MDPI stays neutral with regard to jurisdictional claims in published maps and institutional affiliations.

Copyright: (c) 2021 by the authors Licensee MDPI, Basel, Switzerland. This article is an open access article distributed under the terms and conditions of the Creative Commons Attribution (CC BY) license (https:/ / creativecommons.org/licenses/by/ $4.0 /)$.

\begin{abstract}
The polyelectrolyte poly(sodium 4-styrenesulfonate) undergoes aromatic-aromatic interaction with the drug chlorpheniramine, which acts as an aromatic counterion. In this work, we show that an increase in the concentration in the dilute and semidilute regimes of a complex polyelectrolyte/drug 2:1 produces the increasing confinement of the drug in hydrophobic domains, with implications in single chain thermodynamic behavior. Diafiltration analysis at polymer concentrations between 0.5 and $2.5 \mathrm{mM}$ show an increase in the fraction of the aromatic counterion irreversibly bound to the polyelectrolyte, as well as a decrease in the electrostatic reversible interaction forces with the remaining fraction of drug molecules as the total concentration of the system increases. Synchrotron-SAXS results performed in the semidilute regimes show a fractal chain conformation pattern with a fractal dimension of 1.7 , similar to uncharged polymers. Interestingly, static and fractal correlation lengths increase with increasing complex concentration, due to the increase in the amount of the confined drug. Nanoprecipitates are found in the range of $30-40 \mathrm{mM}$, and macroprecipitates are found at a higher system concentration. A model of molecular complexation between the two species is proposed as the total concentration increases, which involves ion pair formation and aggregation, producing increasingly confined aromatic counterions in hydrophobic domains, as well as a decreasing number of charged polymer segments at the hydrophobic/hydrophilic interphase. All of these features are of pivotal importance to the general knowledge of polyelectrolytes, with implications both in fundamental knowledge and potential technological applications considering aromatic-aromatic binding between aromatic polyelectrolytes and aromatic counterions, such as in the production of pharmaceutical formulations.
\end{abstract}

Keywords: diafiltration; SAXS; aromatic interactions; poly(sodium 4-styrenesulfonate); chlorpheniramine; polyelectrolyte; aggregation

\section{Introduction}

During the last decades, we have studied the interactions between aromatic polyelectrolytes, such as poly(sodium 4-styrenesulfonate) (PSS), and low molecular-weight aromatic species (LMWS) acting as counterions, among which we can find xanthene dyes [1-7], redox-active tetrazolium salts [8-11], and different drugs [12-16]. Both complementary charged species bearing aromatic groups undergo secondary aromatic-aromatic interactions, additional to primary long-range electrostatic interactions, thus producing a reinforcement of the overall interaction. Contrary to the picture given by Manning's 
counterion condensation theory [17-21], in which the territorial binding of counterions to polyelectrolyte chains occurs, aromatic counterions and polymeric aromatic groups produce site-specific binding, losing water molecules from their respective hydration spheres, as deduced by $1 \mathrm{D}$ and $2 \mathrm{D}{ }^{1} \mathrm{H}-\mathrm{NMR}$ spectroscopies $[3-6,8,13,16]$. Verification of the nuclear Overhauser effect allowed for the demonstration that the interacting species approach each other by less than $5 \AA$. Another technique that allowed us to obtain information about the interaction between aromatic polyelectrolytes and low molecular-weight aromatic counterions was diafiltration (DF). This technique is a separation technique, which allowed the direct determination of the counterions bound to the polyelectrolyte in every instant, showing comparatively higher binding and resistance to the cleaving effect of added electrolytes in solution when contrasted with systems that do not undergo aromatic-aromatic interactions $[6,12,13]$. As a consequence of this interaction pattern, some properties of both the counterions and the polymers change, such as aggregation, acid-base, redox, and luminescent properties $[2,4,10,13]$. These interactions have also served to produce interesting higher order structures [11,22-25], and confer different properties to materials [26-31]. In particular, homogenously-dispersed photosensitizers and dyes with a controllable state of aggregation have been included in solid and semisolid materials by means of complexation with an aromatic polyelectrolyte $[7,26,27]$; nanoparticles of redox-active and acid-based reactive aromatic molecules have been produced in the presence of aromatic polyelectrolytes and included in solid and semisolid materials used as sensors $[23,28,30]$.

Drug vehiculization and controlled release in matrices and nanoparticles based on aromatic-aromatic interactions have also been developed [15,16,23]. Importantly, outstanding drug loading of around $50 \%$ has been achieved, since the drug acts both as a bioactive molecule carried by the nanoparticle and as a main constituent of the carrier $[15,16]$. The mechanism for nanocarrier formation involving the dual function of the drug has been rationalized as the consequence of ion pair formation between the charged aromatic drug and the complementary charged polymeric aromatic residues through short-range aromaticaromatic interactions. The occurrence of aromatic-aromatic interactions between the drug chlorpheniramine maleate (CPM) and the polyelectrolyte PSS has been reported in this context $[12-14,16]$. It was found that the extent of binding and the aggregation state of the complexes depend on the absolute and the relative concentration of the reactants. At a PSS concentration of $2 \mathrm{mM}$ (in sulfonate groups per liter) DF showed drug binding of around $80 \%$ in a mixture of PSS/CPM at a sulfonate/drug stoichiometry 2:1 [12,14], forming clear solutions of non-aggregated complexes. On the contrary, at a PSS/CPM stoichiometry 2:3 and $5 \mathrm{mM}$ of the polymer, higher binding, and the formation of nanoparticles were observed [16].

Ion pair formation between both charged aromatic species should imply drastic changes on chain properties in rigid polymers such as PSS. The rigidity of this polymer is due to both electrostatic repulsions between charged groups and the high volume of the aromatic rings, inducing an extended helical conformation of the polymer chain $[32,33]$. Chain properties of PSS have long been studied by SAXS and SANS in the presence of different salts and at several concentrations. Generally, a typical polyelectrolyte peak appears in scattering profiles, whose position depends on the concentration and nature of the counterions [34-38]. However, there are cases in which this typical peak does not appear, related with a high screening of electrostatic repulsions [37-40]. The effect of solvents or sulfonation degree on poly(styrene-co-styrenesulfonate) copolymers has also been studied by SANS and SAXS [41]. SANS and SAXS have been successfully used for the analysis of surfactants, colloids, powders, emulsions, nanocomposites, polymers, and macromolecules in general [42-46], and they offer complementary information to NMR, viscosimetry [47-49], conductimetry [50], and electron microscopies. It is worth mentioning the use of these techniques in complex electron-conductive system based on PSS and poly(3,4-ethylene dioxythiophene) (PEDOT), (PEDOT:PSS), whose chain properties and crystallinity are influenced by the solvent [51-53]. However, despite the different systems containing polymers, whose conformation properties in solution have been studied, there 
is no report in the literature, to the best of our knowledge, concerning the behavior of aromatic polyelectrolyte chains subjected to aromatic-aromatic interactions with aromatic low molecular-weight counterions as a function of the concentration.

In this work, we study the binding, aggregation, and chain properties in the system PSS/CPM at a sulfonate/drug stoichiometry 2:1 as a function of the system concentration in the dilute and semidilute regimes (crossover concentration between $10^{-3}$ and $10^{-2} \mathrm{M}$ (in monomeric units) for PSS) [54,55]. DF results display novel and important features for this analytical tool for analyzing the binding of the drug to the polyelectrolyte. SynchrotronSAXS and Dynamic Light Scattering (DLS) are used as complementary techniques to determine single correlation length chain parameters and the aggregation behavior of the system, respectively. Based on these results, we highlight a model picture for the binding and physicochemical behavior of these aromatic polyelectrolyte-aromatic counterion systems.

\section{Theory}

\subsection{Diafiltration}

Initially conceived as a separation technique for practical purposes [56-59], DF has served to calculate the thermodynamic and kinetic parameters of water-soluble polymers (WSP)/low molecular-weight species (LMWS) complexes after the development of a mathematical model to justify the DF profiles $[2,3,5,8,12,60-62]$. Thus, DF allowed the direct measurement of binding constants between WSP and LMWS, such as aromatic polyelectrolytes and aromatic counterions, providing the measurement of the stabilization effect associated to aromatic-aromatic interactions. A typical DF system is shown in Figure 1. The DF cell containing an aqueous solution of the WSP and the counterions of interest has, at the input, incoming water, and, at the output, a membrane only permeable to the LMWS. Therefore, as DF proceeds, the WSP is washed while the volume in the cell is kept constant. The filtered aqueous LMWS is collected in fractions, which are then quantified to obtain a DF profile as the plot of the natural logarithm of the concentration of the LMWS in the collected DF fractions $\left(\ln <c_{L M W S} s^{\text {filtrate }}>\right)$ versus the filtration factor $(F)$, defined as the ratio between the accumulative filtrate volume and the constant volume in the DF cell.

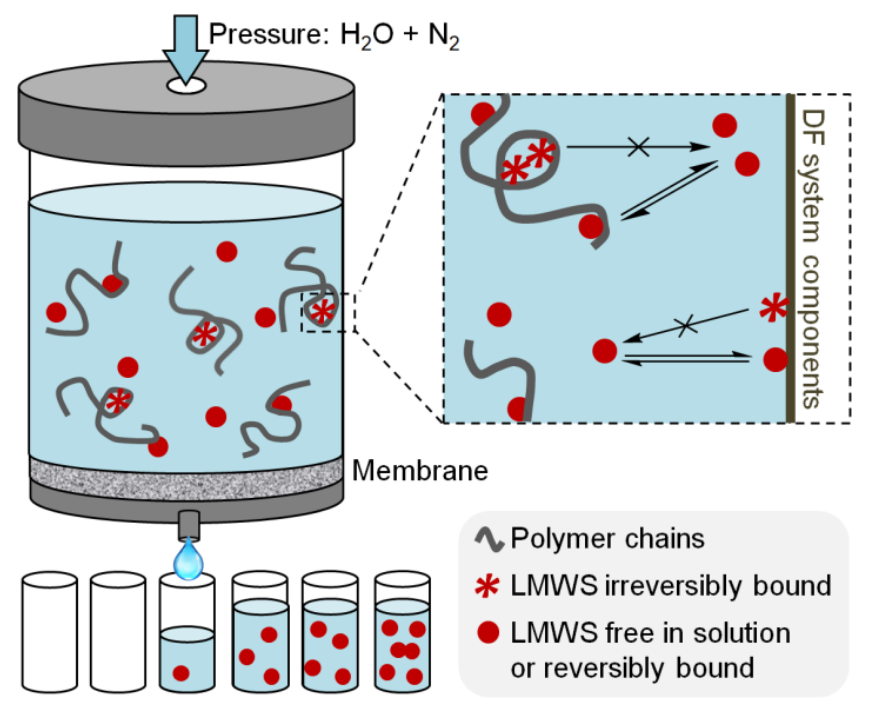

Figure 1. Scheme of a typical diafiltration system (left) and interaction model between low molecularweight species, water-soluble polymers, and the diafiltration system components (right).

Several assumptions are made regarding the interactions between the LMWS and the WSP towards the disclosure of the information concealed in the DF profiles. (1) The total amount of LMWS is distributed in three different populations, namely free in solution, reversibly bound to the WSP (and/or to other components in the DF system), and irreversibly bound to the WSP (and/or to other components in the DF system) (see Figure 1). (2) Fast equilibrium is established between the reversibly bound fraction and the fraction free in the solution, 
so that the steady state approximation can be applied during filtration. (3) Interactions with the DF cell components, including the membrane, are additive to those with the WSP, so that experiments made in the absence of the WSP serve as control. Given these assumptions, a mathematical model fully described in the literature was applied to the DF profiles in order to obtain the information shown below [61-63].

The absolute value of the slope of the DF profile in the absence of the WSP $\left(k^{m}\right)$ is related to the strength of the reversible interactions between the LMWS and the DF system components. Thus, an apparent dissociation constant between the LMWS and the DF system $\left(K_{\text {diss }}{ }^{L M W S / D S}\right)$ can be defined and calculated as shown in Equations (1) and (2), respectively, where $c_{L M W S}{ }^{\text {free }}$ is the concentration of LMWS free in solution, and $c_{L M W S}{ }^{\text {rev-bound-DF }}$ the concentration of LMWS reversibly bound to the DF system components.

$$
\begin{gathered}
K_{\text {diss }}^{L M W S / D S}=\frac{C_{\text {LMWS }}^{\text {free }}}{C_{\text {LMWS }}^{\text {rev-bound }-D S}} \\
K_{\text {diss }}^{\text {LMWS /DS }}=\frac{k^{m}}{1-k^{m}}
\end{gathered}
$$

Similarly, the absolute value of the slope in the presence of the WSP $(j)$ is related with the strength of the reversible interactions between the LMWS and both the WSP and the DF system components. Thus, an apparent dissociation constant between the LMWS and the WSP $\left(K_{\text {diss }}{ }^{L M W S} / W S P\right)$, defined in Equation (3), where $c_{L M W S}$ rev-bound-WSP is the concentration of LMWS reversibly bound to the WSP, can be calculated by applying Equation (4) [62].

$$
\begin{gathered}
K_{\text {diss }}^{\text {LMWS /WSP }}=\frac{C_{\text {LMWS }}^{\text {free }}}{C_{\text {LMWS }}^{\text {rev-bound }-W S P}} \\
\frac{k^{m} j}{k^{m}-j} \leq K_{\text {diss }}^{L M W S / D S} \leq \frac{j}{k^{m}-j}
\end{gathered}
$$

The values of $k^{m}$ and $j$ range between 0 and 1 , lower values meaning stronger interaction. Theoretically $k^{m} \geq j$, so that $K_{\text {diss }}$ LMWS/WSP ranges between $0(j=0)$ and infinite $\left(j=k^{m}\right)$. Values of $j=k^{m}=1$ indicate no interaction with both the DF system components and the WSP.

In Figure 1, the LMWS referred to as irreversibly bound are the molecules that present binding processes that may be reversible with an apparent dissociation constant that tend to zero at the conditions of the experiment or show much slower equilibrium kinetics than the DF process. The fraction of LMWS that is irreversibly bound at the beginning of the DF (i.e., when $F$ tends to 0$)(u)$ is determined from Equation (5), where $b$ is the intercept of the DF profile; $m$, the absolute value of the slope $\left(k^{m}\right.$ or $\left.j\right) ; c_{L M W S}{ }^{\text {cell-init }}$, the total initial LMWS concentration; and $\Delta F$, the difference in $F$ value at which the filtered fractions are collected.

$$
u=1-\frac{b \Delta F}{C_{\text {LMWS }}^{\text {cell-init }}\left(1+e^{m \Delta F}\right)}
$$

By subtracting the $u$ value of control experiments from that of the experiments made in the presence of the WSP, the initial fraction of LMWS irreversibly bound to the WSP is obtained. Likewise, the initial fraction of LMWS that is involved in association-dissociation processes $(v)$ is determined from Equation (6).

$$
v=1-u
$$

\section{2. $S A X S$}

SAXS stands among the most important techniques used to analyze the conformation of polymers in solution. A simplified experimental setup is shown in Figure 2. A collimated X-ray beam impacts the sample, and the elastic component of the scattered beam is detected. The intensity pattern $I$ is the fingerprint of the electron density of the sample and is a con- 
tinuous function of the momentum transfer $q$, i.e., $I=I(q)$. From the analysis and modelling of $I(q)$, one can obtain the characteristic lengths, shape (including surface/volume ratio), assembling state (un/folding, aggregation, internal conformation), crystalline phases with large lattice parameters, and porosity, among other materials characteristics. In SAXS, the detection angle is far below $10^{\circ}$, and, depending on the wavelength of the X-ray beam, one can analyze characteristic dimensions that vary between 1 and $100 \mathrm{~nm}$.

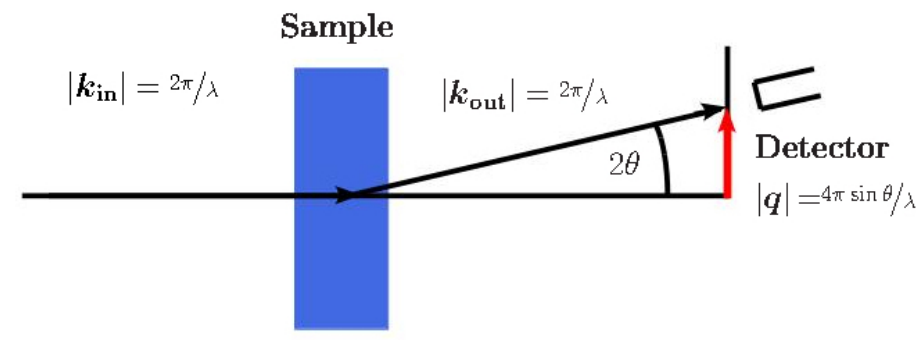

(left)

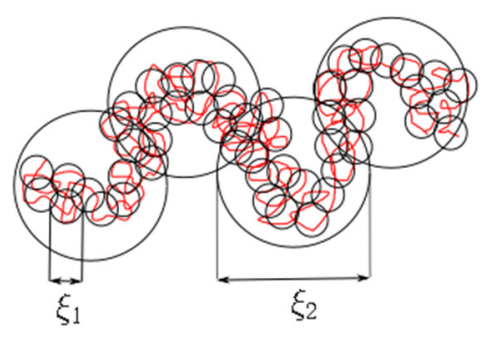

(right)

Figure 2. (Left) SAXS setting with incident and scattered wave vectors, $\left|k_{\text {in }}\right|$ and $\left|k_{\text {out }}\right|$, respectively, and momentum transfer $|q|$; (right): correlation length representing the static screening length, $\xi$, and fractal correlation length for larger domain size, $\xi_{2}$, as determined from Equations (8) and (9).

The theoretical aspects that describe $I(q)$ are reviewed in several papers and books and the reader is directed to them for more information [36,64-66]. In SAXS and SANS experiments, scattering profiles may be analyzed at the very low- $q$ region $\left(q<0.1 \mathrm{~nm}^{-1}\right)$, where the scattering from solidlike density fluctuations is predominant, following the Guinier approximation for spherical particles:

$$
I(q) \approx I_{G}(0) \exp \left[-\left(R_{G}^{2} q^{2}\right) / 3\right]
$$

where $I_{G}(0)$ is the extrapolation of the intensity to $q \rightarrow 0$ from the observed $q$ range, and $R_{G}$ represents the radius of gyration of the polymeric chain, typically of some tenths of $\mathrm{nm}$.

On the other hand, scattering from liquid-like or solution-like density fluctuations may be described by the Ornstein-Zernike scattering function applied in a $q$-range in both low- and high- $q$ regions, where the intermolecular scattering function (the form factor) can be assumed constant $[67,68]$, given by:

$$
I(q)=I_{O Z}(0) /\left[1+\left(q \xi_{1}\right)^{2}\right]
$$

where $I_{O Z}(0)$ is the extrapolation of the intensity to $q \rightarrow 0$ from the observed $q$ range, and $\xi_{1}$ is the correlation length representing the static screening length (see Figure 2), corresponding to the thermal blob size. The exponent 2 is typically obtained for linear polymers in semi-dilute $\theta$-solutions, adopting a random walk conformation [66]. However, a fractal exponent 1.7 (equivalent to $5 / 3$ ) has been also reported to properly describe $I(q)$ for larger domain size $\xi_{2}$ that corresponds to the arrangement of the smaller domains represented by $\xi_{1}$ to swallowed agglomerates (see also Figure 2) [66]. At these scale lengths, the chain conformation is a self-avoiding walk of thermal blobs. Thus, accordingly,

$$
I(q)=I_{O Z}(0) /\left[1+\left(q \xi_{2}\right)^{5 / 3}\right]
$$

Plotting the inverse of $I(q)$, i.e., $I(q)^{-1}$, against $q^{2}$ and $q^{5 / 3}$ as described in Equations (10) and (11), respectively, will lead to straight lines, from which $x_{1}$ and $x_{2}$ can be extracted:

$$
\begin{gathered}
I(q)^{-1}=I_{O Z}(0)^{-1}+I_{O Z}(0)^{-1} \xi_{1}{ }^{2} q^{2} \\
I(q)^{-1}=I_{O Z}(0)^{-1}+I_{O Z}(0)^{-1} \xi_{2}{ }^{5 / 3} q^{5 / 3}
\end{gathered}
$$




\section{Experimental Section}

\subsection{Reagents}

PSS (Aldrich; $\mathrm{M}_{\mathrm{w}}$ 70,000 g/mol; 206.2 g/mol of sulfonate groups, CAS No. 25704-18-1) and PAA (received from Aldrich as poly(acrylic acid) and then neutralized in aqueous solutions by adjusting the $\mathrm{pH}$ value to 7.5 with $\mathrm{NaOH} ; \mathrm{M}_{\mathrm{w}} 450,000 \mathrm{~g} / \mathrm{mol}, 72.06 \mathrm{~g} / \mathrm{mol}$ of acrylic units, CAS No. 9003-01-4) were purified by DF over a regenerated cellulose membrane of a nominal molecular weight limit (NMWL) of 10,000 Da (Millipore). After the polymer solutions were washed at least eight times their initial volume, the solvent was removed by freeze-drying. CPM (Sigma, racemic mixture), $\mathrm{NaOH}$ (Merck), and $\mathrm{HCl}$ (Merck) were used as received. For all experiments and purification procedures, deionized water was used. $\mathrm{NaOH}$ and $\mathrm{HCl}$ were used to adjust the $\mathrm{pH}$. The structures of the polymers and CPM are shown in Figure 3.

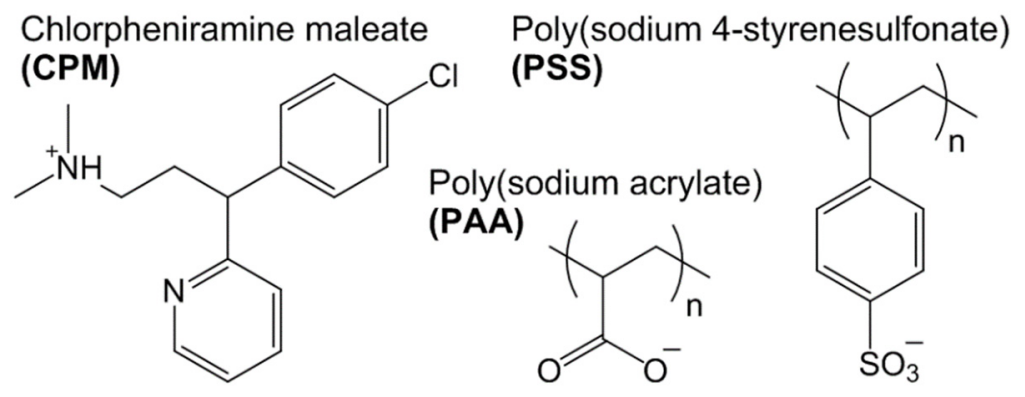

Figure 3. Molecular structure of CPM, PAA, and PSS.

\subsection{Equipment}

The $\mathrm{pH}$ was controlled with a Thermo Fisher Scientific pHmeter (Oakton pH700, Waltham, MA, USA). Dynamic light scattering (DLS) measurements were done in a Nano ZS zetasizer equipment (Malvern, Cambridge, UK) with backscatter detection $\left(173^{\circ}\right)$, controlled by the Dispersion Technology Software (DTS 6.2, Malvern, Cambridge, UK). DF cell Amicon 8010 (10 mL capacity) with a regenerated cellulose DF membrane (Millipore) of a $5000 \mathrm{Da}$ NMWL was used for DF experiments. CPM concentration in the filtration fractions was quantified using He $\lambda$ ios $\gamma$ UV-vis spectrophotometer (Thermo Electron Corporation, Waltham, MA, USA). Synchrotron-SAXS experiments were done in the SAXS1 beamline of the Brazilian Synchrotron Light Laboratory (LNLS) in Campinas, Brazil (Full details of the SAXS line (6 October 2021) are found in https:/ / www.lnls.cnpem.br/facilities/saxs1-en/ accessed on 31 August 2021.

\subsection{Procedures}

\subsubsection{Sample Preparation}

WSP/CPM aqueous solutions with 2:1 molar ratio $\left(\mathrm{WSP}_{n} / \mathrm{CPM}_{\mathrm{n} / 2}, n\right.$ being the polymer concentration in mmol of sulfonate groups per liter $(\mathrm{mM})$ ) were prepared at $\mathrm{pH} 7.5$, and a different total system concentration, with $n$ ranging from 0.25 to $60 \mathrm{mM}$. A set of turbid suspensions of $\mathrm{PSS}_{n} / \mathrm{CPM}_{n / 2}$ complex obtained at PSS concentration of 35,40 , and $50 \mathrm{mM}$ were analyzed by DLS at $25^{\circ} \mathrm{C}$ in triplicate. The hydrodynamic diameter and zeta potential values of the formed particles were considered valid under the criteria of the DTS 6.2 software (Malvern, Cambridge, UK); correlograms of the analyses is shown below.

\subsubsection{Diafiltration Measurements}

A volume of $\mathrm{WSP}_{n} / \mathrm{CPM}_{\mathrm{n} / 2}$ aqueous mixtures $(10 \mathrm{~mL})$, with $n$ ranging from 0.25 to $1.5 \mathrm{mM}$, were placed in a $10 \mathrm{~mL}$ DF cell bearing a $5000 \mathrm{Da}$ NMWL membrane. The $\mathrm{pH}$ in the reservoir was also adjusted to 7.5 . The experiments were performed at room temperature. During the experiment, the volume of the solution $(10 \mathrm{~mL})$ and pressure $(3 \mathrm{bar})$ in the cell were kept constant. Fractions of $5 \mathrm{~mL}$ of the filtered solution were collected and the $\mathrm{CPM}$ concentration was quantified by UV-vis spectroscopy. DF control experiments were 
done in the absence of the WSP to analyze the interaction with the cell components. All experiments were carried out at least in duplicate. The results are expressed as a mean value, and their uncertainty as the standard deviation. The significance of the correlation of the independent variables $u$ and $j$ (and thus $K_{\text {diss }}{ }^{C P M / W S P}$ ) was evaluated by the Pearson correlation coefficient method applied to the experimental data [69].

\subsubsection{Synchrotron-SAXS Measurements}

The above prepared $\mathrm{PSS}_{n} / \mathrm{CPM}_{n / 2}$ aqueous mixtures were injected in the in-vacuum liquid cell available on the beamline, consisting of two mica windows enclosing the solution with $1 \mathrm{~mm}$ X-ray pathlength. The total sample volume was $500 \mu \mathrm{L}$ and the measurements were carried out at room temperature. The beamline energy was set at $8 \mathrm{keV}$, the sample to detector distance was $3 \mathrm{~m}$, resulting in a $q$ range spanning from 0.04 to $1.2 \mathrm{~nm}^{-1}$. The total acquisition time was $1000 \mathrm{~s}$, transmission was corrected, and background was subtracted from all data. Data fitting was done using the free software Python Spyder3. The $q$ domains that satisfy Equations (10) and (11) were searched in order to calculate $\xi_{1}$ and $\xi_{2}$.

\section{Results and Discussion}

\subsection{Sample Preparation and DLS Characterization}

Several samples were prepared with a stoichiometry $\mathrm{WSP}_{\mathrm{n}} / \mathrm{CPM}_{\mathrm{n} / 2}$, and different values of $n$. Samples presenting PSS concentration in the range of $0.5-30 \mathrm{mM}$ resulted in clear solutions. Samples presenting PSS concentration in the range of $40-60 \mathrm{mM}$ precipitated. Between 30 and $40 \mathrm{mM}$ nanoaggregates were found. This did not occur when PAA (pure or with CPM) or pure PSS was used. Figure 4 shows the correlograms of the DLS analyses of the samples $\mathrm{PSS}_{35} / \mathrm{CPM}_{18}, \mathrm{PSS}_{40} / \mathrm{CPM}_{20}$, and $\mathrm{PSS}_{50} / \mathrm{CPM}_{25}$. It can be seen that only the sample $\mathrm{PSS}_{35} / \mathrm{CPM}_{18}$ shows a steady decay on the correlation function. A hydrodynamic diameter of $322 \pm 11 \mathrm{~nm}$ was obtained, with polydispersity index of 0.275 . The zeta potential of the particles took a value of $-30.90 \pm 2.25 \mathrm{mV}$, high enough in absolute value to ensure stability of the aggregate. On the contrary, large, polydisperse particles were visible by the naked eye in the samples $\mathrm{PSS}_{40} / \mathrm{CPM}_{20}$ and $\mathrm{PSS}_{50} / \mathrm{CPM}_{25}$, which produced the shoulders and noisy correlograms at high correlation time values. For the PSS chain, entanglement is reported to occur beyond $100 \mathrm{mM}$ for salt-free PSS $\left(\mathrm{M}_{\mathrm{W}} \sim 100,000 \mathrm{~g} / \mathrm{mol}\right)$ solutions, without undergoing precipitation [44]. Thus, it can be concluded that the presence of CPM and the occurrence of aromatic-aromatic interactions between the drug and PSS enhances polymer aggregation and system collapse in this concentration regime.

\subsection{Diafiltration Analysis}

We performed DF experiments for $\mathrm{PSS}_{n} / \mathrm{CPM}_{n / 2}$ and $\mathrm{PAA}_{n} / \mathrm{CPM}_{n / 2}$ samples in the dilute regime, $n$ between 0.5 and $2.5 \mathrm{mM}$. The corresponding DF profiles are shown in Figure 5, and the corresponding DF parameters are listed in Table 1. All the DF profiles show good linearity, with values of $R^{2} \geq 0.98$. At first sight, it is evident that PSS present much stronger interactions with CPM than PAA. The strength of the reversible interaction is given by the slopes of the profiles, whereas the ordinate at the origin is related with the $u$ value, i.e., with the initial fraction of molecules irreversibly bound to the polymer. The difference between the two polymers regarding the strength of the interaction with CPM stands on the ability of PSS to undergo aromatic-aromatic interactions with the LMWS. 


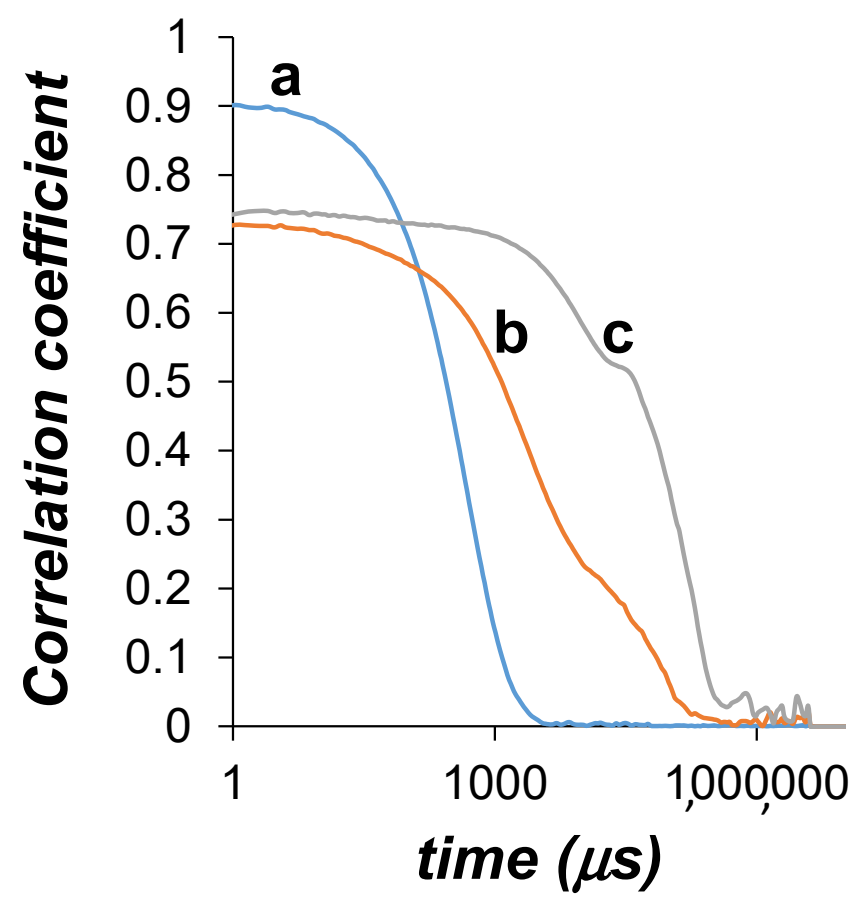

Figure 4. Correlograms obtained by DLS of samples $\mathrm{PSS}_{35} / \mathrm{CPM}_{18}$ (a), $\mathrm{PSS}_{40} / \mathrm{CPM}_{20}$ (b), and $\mathrm{PSS}_{50} / \mathrm{CPM}_{25}$ (c).
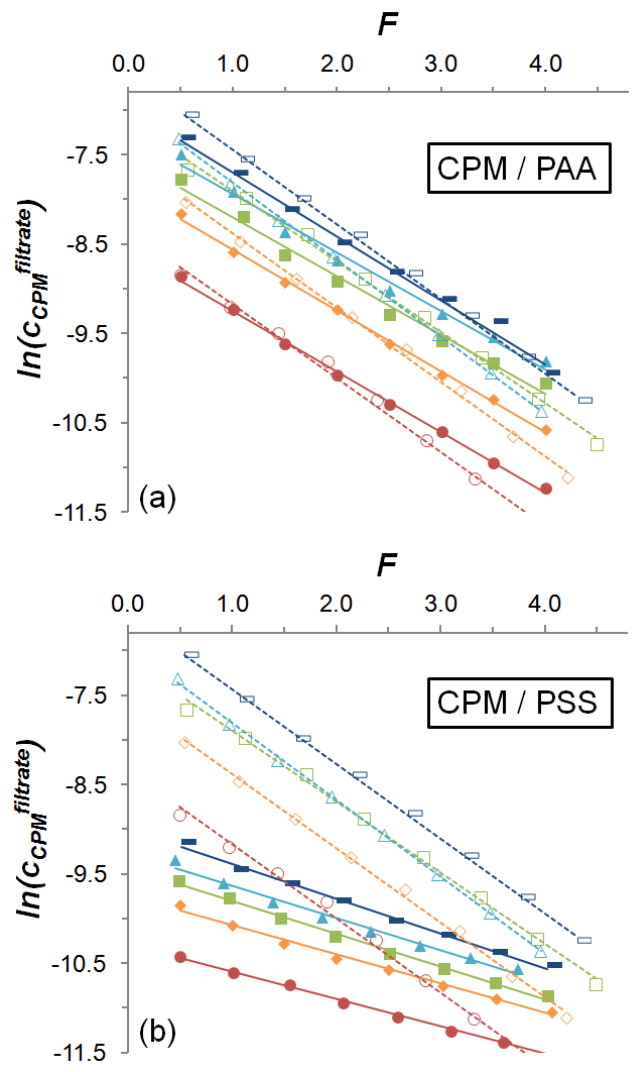

Figure 5. Diafiltration profiles of (a) $\mathrm{PAA}_{n} / \mathrm{CPM}_{\mathrm{n} / 2}$ and (b) $\mathrm{PSS}_{n} / \mathrm{CPM}_{n / 2}$ systems at $n=0.50$ (red circles), 1.0 (orange rhombuses), 1.5 (green squares), 2.0 (light blue triangles), and 2.5 (blue rectangles). Corresponding blank experiments made in the absence of polyelectrolytes are plotted as empty symbols. 
Table 1. $\mathrm{WSP}_{\mathrm{n}} / \mathrm{CPM}_{\mathrm{n} / 2}$ system formulations, the resulting DF parameters, and the linear adjustment of the DF profiles with the corresponding linear regression factors $\left(R^{2}\right)$.

\begin{tabular}{|c|c|c|c|c|c|c|c|c|}
\hline & $\begin{array}{c}c_{C P M}{ }^{\text {total }} \\
\mathrm{mM}\end{array}$ & $\begin{array}{c}c_{W S P}{ }^{\text {total }} \\
\mathrm{mM}\end{array}$ & $v$ & $u$ & $j$ and $\left(k^{m}\right)$ & $\begin{array}{c}K_{\text {diss }}{ }^{L M W S / W S P} \\
\text { and } \\
\left(K_{\text {diss }}{ }^{L M W S / D S}\right)\end{array}$ & Linear Adjustment & $R^{2}$ \\
\hline \multirow{5}{*}{ Blank } & 0.25 & - & 1.03 & -0.03 & $(0.83)$ & $(4.9)$ & $y=-0.83 x-7.6$ & 0.99 \\
\hline & 0.50 & - & 0.97 & 0.03 & $(0.81)$ & (4.3) & $y=-0.81 x-7.6$ & 0.99 \\
\hline & 0.75 & - & 0.94 & 0.06 & $(0.79)$ & (3.8) & $y=-0.79 x-7.1$ & 1.00 \\
\hline & 1.00 & - & 0.94 & 0.06 & $(0.86)$ & (6.1) & $y=-0.86 x-6.9$ & 1.00 \\
\hline & 1.25 & - & 1.03 & 0.03 & $(0.84)$ & (5.3) & $y=-0.84 x-6.6$ & 1.00 \\
\hline \multirow{5}{*}{ PAA } & 0.25 & 0.5 & $0.95 \pm 0.02$ & $0.05 \pm 0.02$ & $0.59 \pm 0.13$ & $2.8 \pm 2.0$ & $(-0.59 \pm 0.13) x+(-8.7 \pm 0.2)$ & $1.00 \pm 0.00$ \\
\hline & 0.50 & 1.0 & $0.89 \pm 0.05$ & $0.11 \pm 0.05$ & $0.63 \pm 0.08$ & $3.5 \pm 1.9$ & $(-0.63 \pm 0.08) x+(-8.0 \pm 0.2)$ & $0.99 \pm 0.01$ \\
\hline & 0.75 & 1.5 & $0.92 \pm 0.02$ & $0.08 \pm 0.02$ & $0.63 \pm 0.04$ & $3.7 \pm 1.1$ & $(-0.63 \pm 0.04) x+(-7.6 \pm 0.1)$ & $0.98 \pm 0.01$ \\
\hline & 1.00 & 2.0 & $0.88 \pm 0.01$ & $0.12 \pm 0.01$ & $0.62 \pm 0.04$ & $2.5 \pm 0.6$ & $(-0.62 \pm 0.04) x+(-7.4 \pm 0.1)$ & $0.99 \pm 0.00$ \\
\hline & 1.25 & 2.5 & $0.86 \pm 0.01$ & $0.14 \pm 0.01$ & $0.69 \pm 0.04$ & $4.5 \pm 1.5$ & $(-0.69 \pm 0.04) x+(-7.0 \pm 0.1)$ & $0.99 \pm 0.00$ \\
\hline \multirow{5}{*}{ PSS } & 0.25 & 0.5 & $0.41 \pm 0.00$ & $0.59 \pm 0.00$ & $0.28 \pm 0.03$ & $0.48 \pm 0.07$ & $(-0.28 \pm 0.03) x+(-10.4 \pm 0.1)$ & $0.98 \pm 0.02$ \\
\hline & 0.50 & 1.0 & $0.39 \pm 0.08$ & $0.61 \pm 0.08$ & $0.30 \pm 0.04$ & $0.54 \pm 0.11$ & $(-0.30 \pm 0.04) x+(-9.7 \pm 0.1)$ & $0.98 \pm 0.01$ \\
\hline & 0.75 & 1.5 & $0.27 \pm 0.01$ & $0.73 \pm 0.01$ & $0.35 \pm 0.02$ & $0.70 \pm 0.09$ & $(-0.35 \pm 0.02) x+(-9.5 \pm 0.0)$ & $0.99 \pm 0.00$ \\
\hline & 1.00 & 2.0 & $0.27 \pm 0.01$ & $0.73 \pm 0.01$ & $0.37 \pm 0.01$ & $0.69 \pm 0.03$ & $(-0.37 \pm 0.10) x+(-9.2 \pm 0.1)$ & $0.98 \pm 0.00$ \\
\hline & 1.25 & 2.5 & $0.24 \pm 0.02$ & $0.76 \pm 0.02$ & $0.38 \pm 0.00$ & $0.78 \pm 0.01$ & $(-0.38 \pm 0.00) x+(-9.0 \pm 0.1)$ & $0.99 \pm 0.01$ \\
\hline
\end{tabular}

The DF parameters $v, u, k^{m}, j, K_{\text {diss }}{ }^{L M W S / D S}$, and $K_{\text {diss }}{ }^{L M W S / W S P}$ listed in Table 1 show, for blank experiments, $u$ values very close to zero and $k_{m}$ values in the range of $0.79-0.86$, indicating that there is no CPM irreversibly bound to the cell components, and that weak reversible interactions occur with the system components, with apparent dissociation constants $\left(K_{\text {diss }}{ }^{C P M / D S}\right)$ higher than 3.8. In the case of $\mathrm{PAA}_{\mathrm{n}} / \mathrm{CPM}_{\mathrm{n} / 2}$ mixtures, low $u$ values are also found, ranging from 0.05 to 0.14 , as well as relatively high $j$ values, ranging between 0.59 and 0.69 , also indicating weak interaction forces, with $K_{\text {diss }}{ }^{C P M / P A A}$ higher than 2.5. On the contrary, for the $\mathrm{PSS}_{\mathrm{n}} / \mathrm{CPM}_{\mathrm{n} / 2}$ mixtures, relatively high $u$ values are found, ranging between 0.59 and 0.76 , indicating that a significant initial fraction of the drug is irreversibly confined in the polymer domain. In addition, the fraction subjected to reversible binding presented $K_{\text {diss }}{ }^{C P M / P S S}$ ranging between 0.48 and 0.78 , related with $j$ values ranging between 0.28 and 0.38 , showing that the fraction of molecules in equilibrium that are bound to the polyelectrolyte is significantly higher than that of molecules free in solution.

It can be seen that, as the concentration of the $\mathrm{PSS}_{\mathrm{n}} / \mathrm{CPM}_{\mathrm{n} / 2}$ system increases, $u$ takes higher values (Figure 6a), indicating that a higher fraction of the total initial CPM molecules is irreversibly bound to the polymer at higher total concentration. A similar effect is found for the system $\mathrm{PAA}_{\mathrm{n}} / \mathrm{CPM}_{\mathrm{n} / 2}$, in the low range of $u$ values, presenting a smaller growth and higher relative standard deviations. The values of $j$, along with $K_{d i s s}{ }_{C P M / W S P}$, also significantly increase as $n$ increases, revealing that the fraction of reversible bound molecules, in addition to decreasing with respect to the irreversibly bound fraction, is less tightly bound to the polymer (Figure $6 \mathrm{~b}, \mathrm{c}$ ). On the contrary, the data obtained for the $\mathrm{PAA}_{n} / \mathrm{CPM}_{n / 2}$ system present considerable standard deviations, which prevent concluding a tendency for these two parameters.

These findings represent an interesting novelty in the development of DF as an analytical technique. The mathematical analysis of the DF profiles does not anticipate a direct physical correlation between $j$ (or $K_{\text {diss }}{ }^{L M W S} / W S P$ ) and $u$, i.e., between the strength of the reversible interactions and the fraction of molecules irreversibly bound to the polymer. However, a definite correlation between $u$ and $j$ (and $K_{\text {diss }}{ }^{C P M / P S S}$ ) values for the $\mathrm{PSS}_{\mathrm{n}} / \mathrm{CPM}_{\mathrm{n} / 2}$ system is found. Indeed, a linear dependency of $j$ (and $K_{\text {diss }}{ }^{C P M / P S S}$ ) with $u$ is found with good linear regression factors in the range of concentration studied, as can be seen in Figure $6 \mathrm{~d}$. Pearson correlation coefficients of over 0.94 indicate a statistically significant linear positive correlation for both cases [69]. These results indicate that, for this system, the magnitudes represented by $u$ and $j$, and thus $K_{\text {diss }}{ }_{C P M} / P S S$, are physically linked, so that their values are directly correlated through the $\mathrm{PSS}_{n} / \mathrm{CPM}_{\mathrm{n} / 2}$ mixture's initial concentration. 

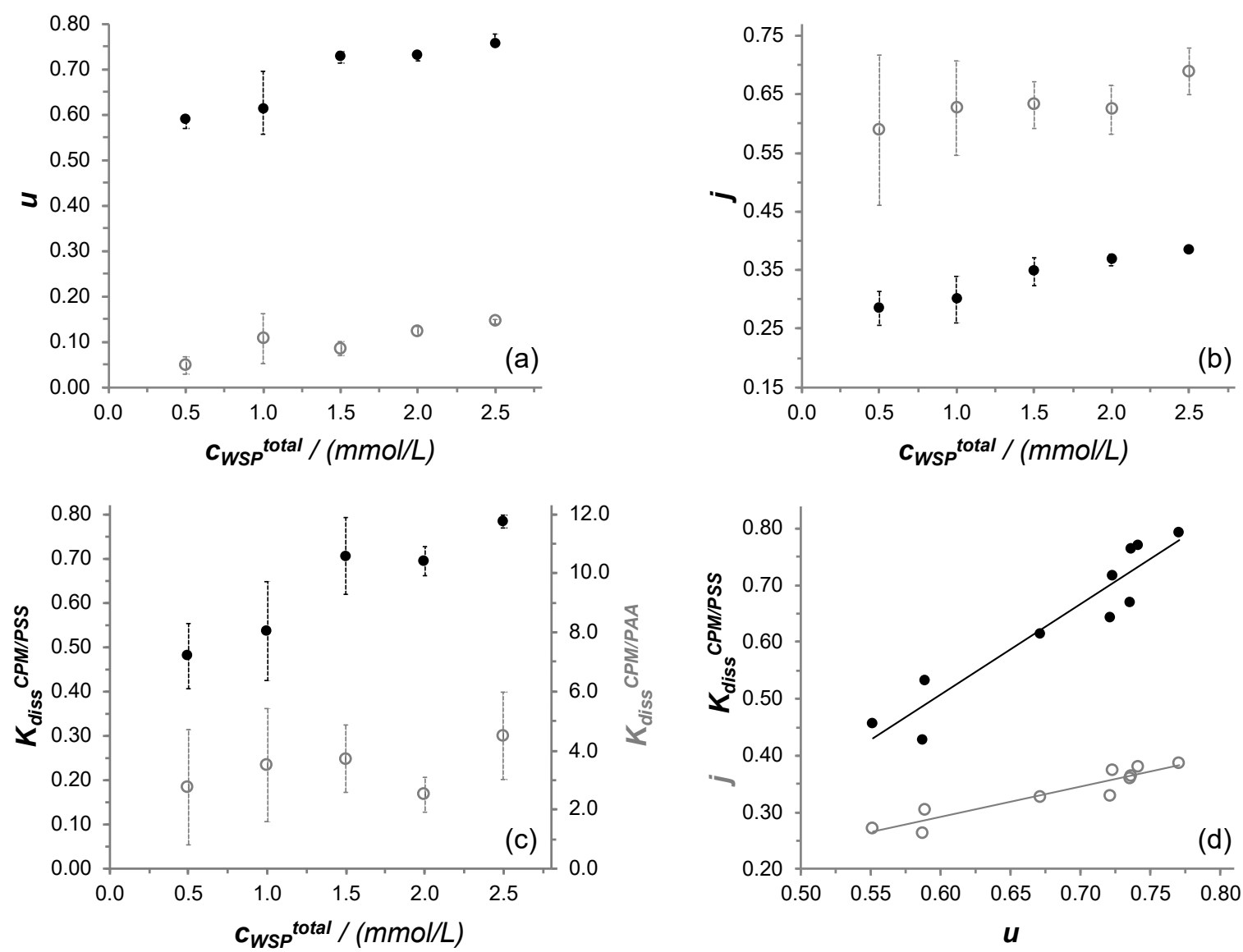

Figure 6. $u$ values (a), $j$ values (b), and $K_{\text {diss }}{ }^{C P M / W S P}$ values (c), plotted against the initial polyelectrolyte concentration $\left(c_{W S P}{ }^{\text {total }}\right)$ for $\mathrm{PAA}_{\mathrm{n}} / \mathrm{CPM}_{\mathrm{n} / 2}$ (grey empty circles) and $\mathrm{PSS}_{\mathrm{n}} / \mathrm{CPM}_{\mathrm{n} / 2}$, systems (black circles). $K_{\text {diss }}{ }^{C P M / P S S}$ (black circles) $\left(\mathrm{y}=1.6 \mathrm{x}-0.44 ; R^{2}=0.90\right)$ and $j$ (grey empty circles) $\left(\mathrm{y}=0.53 \mathrm{x}-0.029 ; R^{2}=0.89\right)$ values plotted against $u$ (plotting each individual experiment for all $\mathrm{PSS}_{\mathrm{n}} / \mathrm{CPM}_{\mathrm{n} / 2}$ systems) (d).

\subsection{SAXS Analysis}

Figure 7A shows SAXS results of the experimental scattering intensity $I(q)$ as a function of the modulus of the momentum transfer vector $q$ for five distinctive $\mathrm{PSS}_{\mathrm{n}} / \mathrm{CPM}_{\mathrm{n} / 2}$ concentrations, with $n$ ranging from 0.5 to $60 \mathrm{mM}$.

It can be seen in Figure 7A that the typical polyelectrolyte peak of PSS is not present in the $\mathrm{PSS}_{\mathrm{n}} / \mathrm{CPM}_{\mathrm{n} / 2}$ complexes. The first two plots $a$ and $b$ correspond to low concentrated samples. The scattering of sample $c$, corresponding to $\mathrm{PSS}_{10} / \mathrm{CPM}_{5.0}$, yet in the typical concentration range at which many studies are reported in the literature $[37,38]$, is significantly more intense. Sample $d, \mathrm{PSS}_{35} / \mathrm{CPM}_{18}$, shows in DLS a scattering pattern that is consistent with the formation of colloidal particles of nanometric size (around $300 \mathrm{~nm}$, see Figure 4). These new conglomerates pop out in the SAXS profile as a small shoulder beginning at $q \sim 0.06 \mathrm{~nm}^{-1}$. The shoulder is more clearly observed in sample $e$, $\mathrm{PSS}_{60} / \mathrm{CPM}_{30}$, corresponding to a system concentration at which the polymeric complexes display macroprecipitation.

The total scattering function has a positive component related with intrachain interactions and a negative component related with repulsive interchain interactions [38]. The disappearance of the polyelectrolyte peak for PSS in the presence of a large excess of $\mathrm{NaCl}$ or other metal counterions is explained by an increase in the compressibility of the polymeric chains and fluctuations of the interparticle distances which rises the intensity in the low- $q$ region, and the increase in the fluctuations of the intersegmental distance, increasing the scattering intensity in the high- $q$ region $[38,70]$. These effects have also been observed in the presence of divalent metal counterions where electrostatic attraction is stronger and 
the screening more intense $[34,37,71,72]$. The screening of electrostatic repulsive forces producing polymeric systems of neutral-like behavior is invoked, then, to explain the polyelectrolyte peak disappearance $[38,72,73]$. An interesting theoretical study analyzing expected SAXS profiles for different systems as a function of the form factor and the Bjerrum length has been reported [74]. Scattering profiles similar to those reported here are shown for polyelectrolyte systems bearing relatively high Bjerrum length, corresponding to sausage single chain conformations, provided that interchain interactions are considered negligible. However, models considering attractive interchain interactions and clustering have also been reported to be consistent with fluctuating transient aggregates that could fit to the SAXS profiles reported in this work $[34,35,37,73,75]$. Similar scattering profiles can be also found for rigid polyelectrolytes such as DNA [72], chondroitin sulfate, hyaluronate, or poly(aspartate) [68], proteins [76], coacervate interpolymer complexes [40,77], and even nonionic micelles formed in water [78].
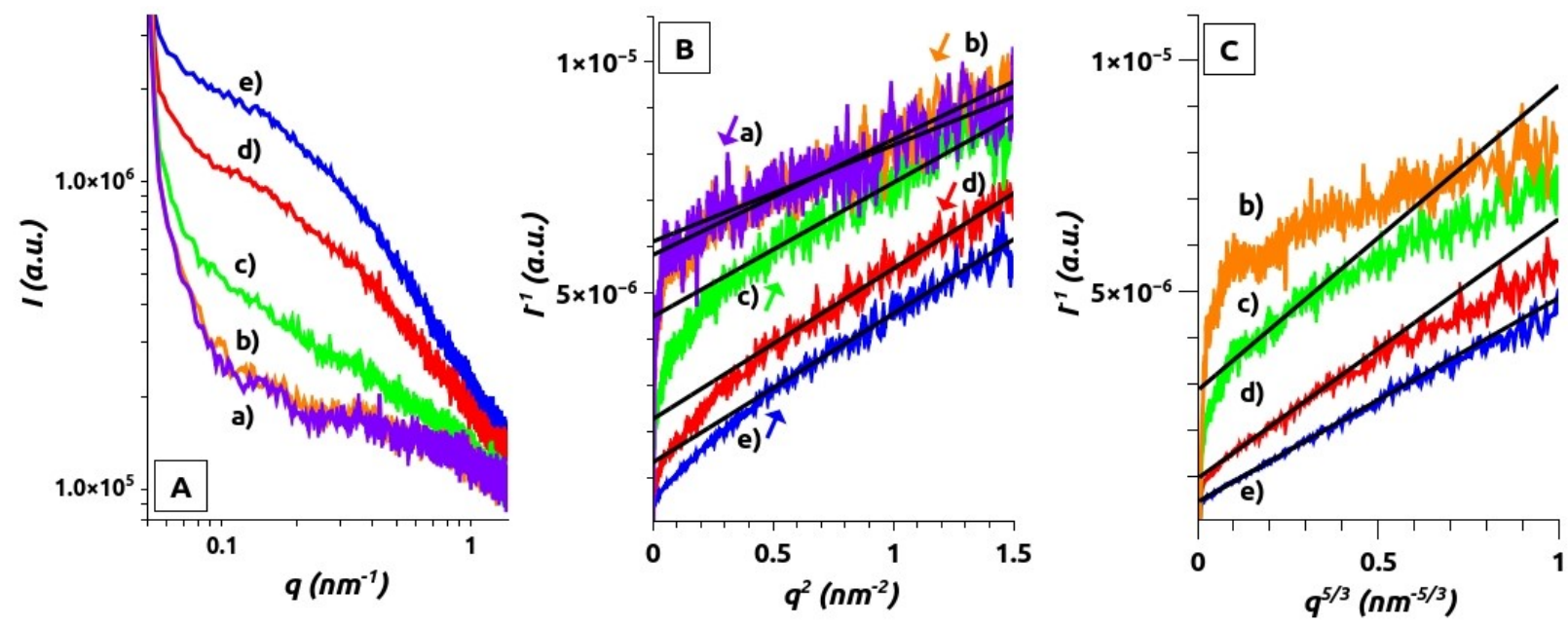

Figure 7. Synchrotron-SAXS results for selected $\mathrm{PSS}_{\mathrm{n}} / \mathrm{CPM}_{\mathrm{n} / 2}$ concentration values: (A) $I(q)$ vs. $q ;\left(\right.$ B) $I(q)^{-1}$ vs. $q^{2}$, and fitted curves obtained applying Equation (10) to a set of $\left(I(q)^{-1}, q^{2}\right)$ values; (C) $I(q)^{-1}$ vs. $q^{5 / 3}$ and fitted curves obtained applying Equation (11) to a set of $\left(I(q)^{-1}, q^{5 / 3}\right.$ ) values. (a) $P S S_{0.5} / C P M_{0.25}$ (mauve), (b) $P S S_{2.0} / C P M_{1.0}$ (orange), (c) $P S S_{10} / C P M_{5.0}$ (green), (d) $P S S_{35} / C P M_{18}$ (red), (e) $P S S_{60} / C P M_{30}$ (blue).

Table 2 summarizes the $\xi_{1}$ and $\xi_{2}$ values obtained from curve fitting to Equations (10) and (11). The Ornstein-Zernike analysis shows good correlation of $I(q)^{-1}$ vs. $q^{2}$ for an extended range of data (see Figure $7 \mathrm{~B}$ ). The two more dilute samples seem to follow the signature of a Gaussian chain for a random walk conformation in a dilute environment. In addition, for samples where $n$ is equal to or higher than 10, including those where nanoand macroprecipitates are observed, an also extended set of $I(q)^{-1}$ data correlates well with $q^{5 / 3}$ (Equation (11)), as observed in Figure 7C, showing a single polymer chain interacting equally well with itself and with the solvent producing self-avoiding walk conformations, characteristic of a fully swollen coil (Figure 2).

Table 2. $\xi_{1}$ and $\xi_{2}$ correlation lengths for different $\mathrm{PSS}_{\mathrm{n}} / \mathrm{CPM}_{\mathrm{n} / 2}$ system formulations.

\begin{tabular}{|c|c|c|c|c|c|c|}
\hline $\begin{array}{l}\mathrm{PSS}_{\mathrm{n}} / \mathrm{CPM}_{\mathrm{n} / 2} \\
(\mathrm{mM} / \mathrm{mM})\end{array}$ & $\begin{array}{l}q \text { Range for Equation (10) } \\
\qquad\left(\mathrm{nm}^{-1}\right)\end{array}$ & $R^{2}$ & $\xi_{1} \pm \delta \xi_{1}(\mathrm{~nm})$ & $\begin{array}{l}q \text { Range for Equation (11) } \\
\left(\mathrm{nm}^{-1}\right)\end{array}$ & $R^{2}$ & $\xi_{2} \pm \delta \xi_{2}(\mathrm{~nm})$ \\
\hline $0.5 / 0.25$ & $0.49-1.23$ & 0.78 & $0.60 \pm 0.01$ & - & - & - \\
\hline $2.0 / 1.0$ & $0.53-1.27$ & 0.90 & $0.70 \pm 0.01$ & - & - & - \\
\hline $10 / 5.0$ & $0.61-1.22$ & 0.90 & $0.80 \pm 0.01$ & $0.20-0.52$ & 0.924 & $1.70 \pm 0.02$ \\
\hline $20 / 10$ & $0.67-1.19$ & 0.94 & $1.00 \pm 0.01$ & $0.22-0.53$ & 0.978 & $2.30 \pm 0.03$ \\
\hline $30 / 15$ & $0.74-1.21$ & 0.85 & $1.10 \pm 0.02$ & $0.20-0.54$ & 0.976 & $2.70 \pm 0.05$ \\
\hline $35 / 18$ & $0.74-1.21$ & 0.95 & $1.20 \pm 0.02$ & $0.20-0.55$ & 0.989 & $2.90 \pm 0.03$ \\
\hline $40 / 20$ & $0.73-1.20$ & 0.94 & $1.20 \pm 0.02$ & $0.20-0.55$ & 0.992 & $3.00 \pm 0.04$ \\
\hline $50 / 25$ & $0.73-1.20$ & 0.97 & $1.40 \pm 0.02$ & $0.20-0.55$ & 0.993 & $3.40 \pm 0.03$ \\
\hline $60 / 30$ & $0.67-1.17$ & 0.98 & $1.50 \pm 0.02$ & $0.18-0.53$ & 0.995 & $4.0 \pm 0.1$ \\
\hline
\end{tabular}


Figure 8 summarizes the correlation lengths obtained for the whole set of samples. The primary smaller thermal blobs showed static correlation lengths $\xi_{1}$ in the range of $0.5-1.5 \mathrm{~nm}$, growing monotonously with the total concentration of the system. On the other hand, the secondary larger domains showed fractal correlation lengths $\xi_{2}$ in the range of $1.0-4.0 \mathrm{~nm}$, also growing monotonously with the total concentration of the system, showing a larger rate, as compared to the primary blobs. This behavior is outstanding since the increase in the concentration of the system normally produces shrinking of the polymer chains and a decrease in the correlation lengths $[68,70]$.

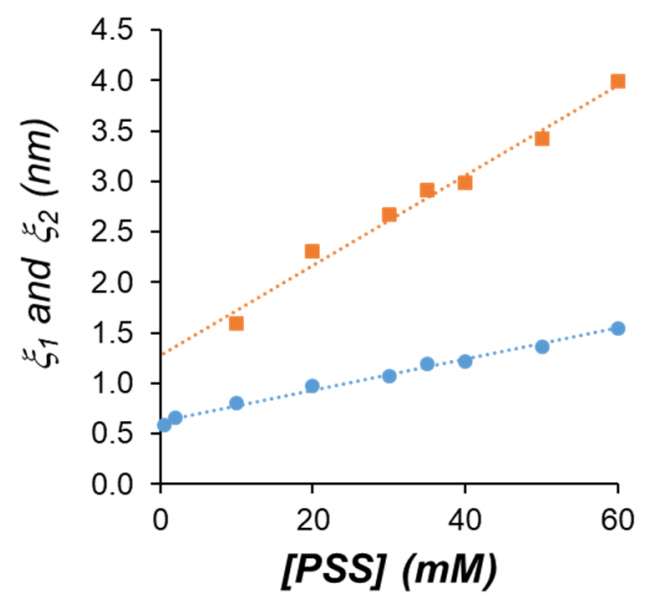

Figure 8. Correlation lengths $\xi_{1}$ (circles) and $\xi_{2}$ (squares) obtained from Equations (10) and (11), respectively. Linear regression functions are y $=0.0153+0.6238\left(R^{2}=0.99\right)$ for $\xi_{1}$ vs. [PSS] and $\mathrm{y}=0.0447+1.2751\left(R^{2}=0.98\right)$ for $\xi_{2}$ vs. [PSS].

\subsection{Aromatic WSP/Aromatic Counterion Complexation and Aggregation Model}

At the concentration range of the experiments shown here for DF and synchrotronSAXS, pure PSS does not form aggregates [44]. However, the occurrence of site-specific aromatic-aromatic interactions between CPM and the benzenesulfonate groups of PSS produces the decrease in the effective charge density of the polymer chains favoring intrachain attractive interactions and decreasing interchain repulsions, increasing the tendency of the macromolecule to fold. To explain the results shown in this paper, we should invoke the short-range character of aromatic-aromatic interactions. This involves the release of water from the hydration sphere of $\mathrm{CPM}$ and polymeric benzenesulfonate groups upon binding, producing ion pair formation. These ion pairs show a tendency to aggregate in hydrophobic domains. As depicted in Figure 9, these hydrophobic domains, composed of ion pairs and polymeric backbone folds and bundles, although transient, should contain the irreversibly bound fraction of CPM observed by DF and essentially determine the size of the thermal blobs related to the static screening length $\xi_{1}$. The remaining charged hydrated polymeric segments provide charge for the system stabilization in water and the reversible interaction with the remaining fraction of the LMWS.

The confinement of CPM in hydrophobic domains increases with the system concentration, which should enhance both the compressibility of the system and intersegmental interactions [79]. The correlation between $u$ and $j$ in DF experiments indicates that polymer chains fold and ion pairs aggregate in hydrophobic domains, confining a higher number of CPM molecules in polymeric blobs (increasing the value of the $u$ parameter). As more benzenesulfonate/CPM ion pairs are confined in hydrophobic domains, the net charge of the polymeric particles decreases, decreasing the strength of the interaction with the non-confined fraction of the LMWS (increasing the value of the $j$ parameter). Together with an increase in the system concentration, an arrangement of the polymeric chain containing the thermal blobs into swollen agglomerates represented by the characteristic length $\xi_{2}$ occurs. It is interesting to note that both $\xi_{1}$ and $\xi_{2}$ do increase with the total concentration. Short-range aromatic-aromatic interaction with the drug CPM should influence the size and 
mobility of the PSS segments. The thermal blobs, involving a higher number of unhydrated ion pairs stabilized in hydrophobic domains as the concentration increases, grow, and it is probable that they form clusters due to a certain tendency of CPM to self-aggregate [80]. These facts may be responsible for the increase in the thermal blob size, which further triggers an increase in the swollen fractal blobs size.

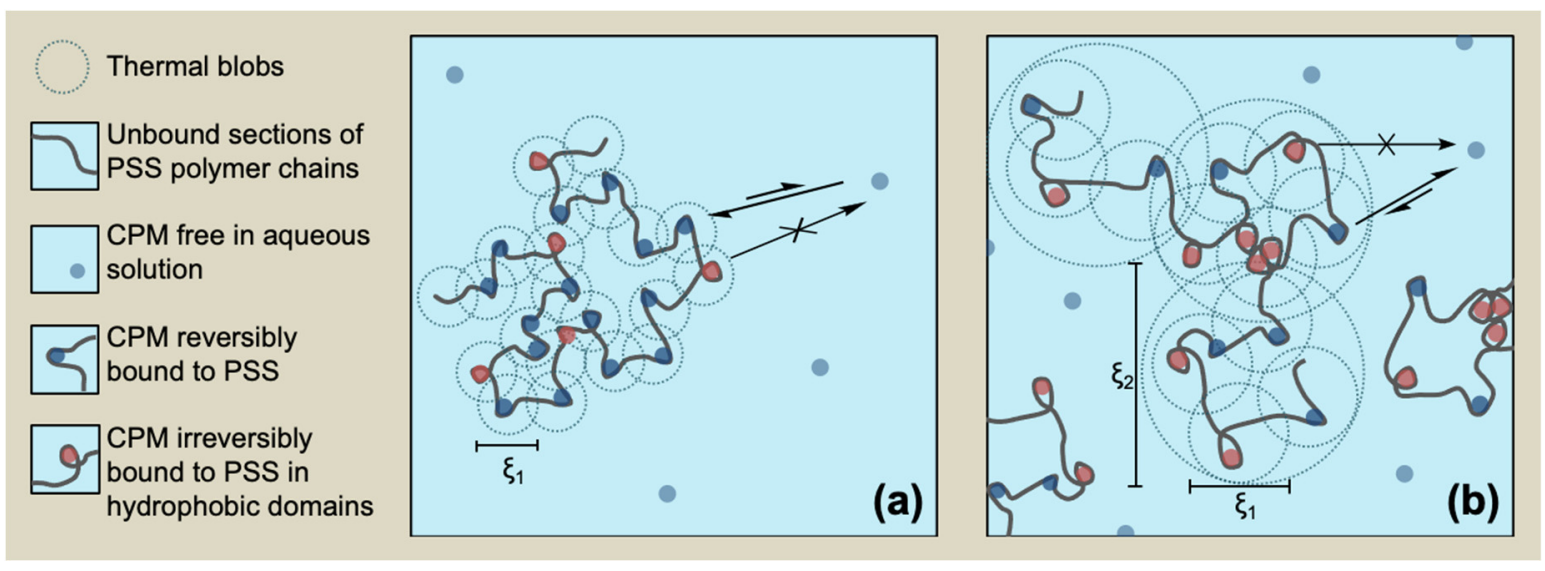

Figure 9. Molecular diagram of the $\mathrm{PSS}_{n} / \mathrm{CPM}_{n / 2}$ system at different concentrations where $\xi_{1}$ and $\xi_{2}$, as well as the irreversibly bound fraction of CPM confined in folds and bundles of the polyelectrolyte chain increase at an increasing system concentration: (a) dilute regime; (b) semidilute regime.

Finally, when the net charge of the particles decreases below a certain value, interchain interactions become more favorable than chain-solvent interactions, the persistence length of the electrostatic interactions is favored over the entropic effect, and the $\mathrm{PSS}_{n} / \mathrm{CPM}_{n / 2}$ complex precipitates $[44,79]$.

\subsection{Final Remarks}

Here, we successfully showed a statistically significant linear correlation between $j$ (and $K_{\text {diss }}{ }^{C P M / P S S}$ ) and $u$ for an aromatic WSP/aromatic LMWS system over a specific range of concentrations. In addition, we have shown the variation of the static and fractal correlation distances describing the behavior of the polymeric chains in the complex. Put together, the results shown here point at a binding and aggregation model that assumes the formation of hydrophobic domains upon the aggregation of polymeric hydrophobic segments and ion pairs formed through aromatic-aromatic interactions between the aromatic LMWS and the aromatic WSP. These separate domains, that may be considered to be two phases [35], consist of dynamic arrangements arising upon molecular interaction and aggregation: a discontinuous and transient inner hydrophobic phase, containing mainly the irreversibly bound fraction of LMWS confined in hydrophobic domains composed by ion pairs and polymeric backbone folds and bundles, and the hydrophilic phase, composed of the continuous aqueous phase. The interphase is composed by the remaining charged hydrated polymeric segments, which provides the system stabilization in water, and contains the reversibly bound counterions. Examples of two-phase aggregated systems have been described in the literature formed with PSS and cationic surfactants $[39,81-83]$. In addition to the study of polyelectrolyte/counterion interactions, DF has been shown to be a useful technique used to study interactions in nanophase-separated systems such nanodroplets of oily core stabilized by anionic and cationic surfactants interacting with the antibiotic oxytetracycline [63].

The binding model presented here, consistent with DLS, DF, and synchrotron-SAXS results, may be relevant for the interpretation of out-of-equilibrium processes in which the solvent is removed, so that the concentration of the complex increases, keeping the LMWS/WSP ratio constant. This may contribute to new knowledge involving material design and application, material properties, and functionality projection in fields such as 
agriculture, sensors, photocatalysts, environmental remediation, etc. Regarding drugs, the behavior of medicines based on aromatic polyelectrolytes/aromatic drug complexes interpreted under this binding model may contribute to the design of controlled drug delivery materials. In particular, it allows for the interpretation of the formation of pharmaceutical nanoformulations, in which outstanding high drug loading is achieved in nanocarriers (of around 50\%), since the drug acts both as a bioactive molecule carried by the nanoparticle, and as a main constituent of the carrier [15].

\section{Conclusions}

As the concentration of the mixture PSS/CPM 2:1 in water increases in the dilute and semidilute regimes, a higher amount of CPM confines in the polymer domain. At polymer concentrations between 0.5 and $2.5 \mathrm{mM}$, the strength of the $\mathrm{PSS}_{\mathrm{n}} / \mathrm{CPM}_{\mathrm{n} / 2}$ reversible interactions given by $j$ (and thus $K_{\text {diss }}{ }^{C P M / P S S}$ ) and the irreversibly bound fraction of CPM bound to PSS $(u)$ are directly correlated, showing a linear tendency of positive slope (with Pearson correlation coefficients over 0.94), evidenced upon increasing the system total concentration. Thus, $u, j$, and $K_{\text {diss }} C P M / P S S$ increase along with the system total concentration. Lower affinity is found for CPM and the non-aromatic polyelectrolyte PAA, thus $j$ and $K_{\text {diss }}{ }_{C P M / P A A}$ values showed high standard deviations, and correlations with $u$ could not be found, highlighting the role of aromatic-aromatic interactions in the system behavior. Synchrotron-SAXS results display an outstanding increase in characteristic chain correlation lengths, static screening lengths $\xi_{1}$ in the range $0.5-1.5 \mathrm{~nm}$, and correlation lengths $\xi_{2}$ in the range of 1-4 $\mathrm{nm}$, following an aggregation pattern with a fractal dimension of 1.7. Nanoprecipitates of around $300 \mathrm{~nm}$ are found in the range of 30-40 mM, and macroprecipitates are found at a higher system concentration. A binding model has been proposed to interpret these results, so that, due to aromatic-aromatic interactions, the probability of ion pair formation between CPM and the benzene sulfonate groups of PSS increases with the total concentration of the system, as well as the probability of their aggregation. Therefore, hydrophobic domains are increasingly formed where a larger fraction of the CPM becomes irreversibly confined. Additionally, as the hydrophobic domains increase, less polyelectrolyte charged segments are available at the interface, so that the attraction of CPM molecules free in solution decreases, and the reversible interaction between the opposite charged species weakens. The increase in the drug confinement should be responsible for the increase in the static and fractal correlation lengths, observed in the increasing concentrations of the complex, and also weakens the interaction of the polymer chains with the solvent, producing precipitation at the highest concentrations evaluated. These findings contribute to the general knowledge of polyelectrolytes, with implications both in fundamental knowledge and potential technological applications considering aromaticaromatic binding between aromatic polyelectrolytes and aromatic counterions, and, in particular, in the design of new pharmaceutical nanoformulations with outstanding high drug loading.

Author Contributions: Conceptualization, F.O. and I.M.-V.; methodology, F.O., T.H., M.E.F., J.G.L. and I.M.-V.; software, T.H., M.E.F. and J.G.L.; formal analysis, F.O., T.H., M.E.F., J.G.L. and I.M.-V.; investigation, F.O., T.H., M.E.F., J.G.L. and I.M.-V.; resources, J.R.V.-B., J.G.L., M.E.F. and I.M.-V.; data curation, F.O., T.H., M.E.F., J.G.L. and I.M.-V.; writing-original draft preparation, F.O., T.H. and I.M.-V.; writing—review and editing, F.O., T.H., M.E.F., J.G.L., J.R.V.-B. and I.M.-V.; validation, F.O., T.H., M.E.F., J.G.L. and I.M.-V.; visualization, F.O., J.G.L., T.H. and I.M.-V.; supervision, I.M.-V.; project administration, I.M.-V.; funding acquisition, J.R.V.-B., J.G.L., M.E.F. and I.M.-V. All authors have read and agreed to the published version of the manuscript.

Funding: This research was funded by Fondecyt Regular No. 1150899, 1181695, and 1210968, and Fondecyt Iniciación No. 11181029.

Institutional Review Board Statement: Not applicable.

Informed Consent Statement: Not applicable. 
Acknowledgments: We thank Bernal Sibaja for helpful discussions regarding this work. J.L. and M.F. are grateful for the support of LNLS through project No. 20170181 and 20180276 that allowed accessing the Synchrotron-SAXS facilities in Campinas-Brazil. We particularly appreciate the technical support of Florian Meneau who helped in defining the SAXS experiments together with the correction to the technical aspects of the Synchrotron-SAXS experimental setup.

Conflicts of Interest: The authors declare no conflict of interest.

\section{References}

1. Moreno-Villoslada, I.; Flores, M.E.; Marambio, O.G.; Pizarro, G.d.C.; Nishide, H. Polyaromatic-Anion Behavior of Different Polyelectrolytes Containing Benzenecarboxylate Units. J. Phys. Chem. B 2010, 114, 7753-7759. [CrossRef]

2. Moreno-Villoslada, I.; González, F.; Arias, L.; Villatoro, J.M.; Ugarte, R.; Hess, S.; Nishide, H. Control of CI Basic Violet 10 aggregation in aqueous solution by the use of poly (sodium 4-styrenesulfonate). Dye. Pigment. 2009, 82, 401-408. [CrossRef]

3. Moreno-Villoslada, I.; González, R.; Hess, S.; Rivas, B.L.; Shibue, T.; Nishide, H. Complex formation between rhodamine B and poly (sodium 4-styrenesulfonate) studied by 1H-NMR. J. Phys. Chem. B 2006, 110, 21576-21581. [CrossRef] [PubMed]

4. Moreno-Villoslada, I.; Jofré, M.; Miranda, V.; Chandía, P.; González, R.; Hess, S.; Rivas, B.L.; Elvira, C.; San Román, J.; Shibue, T. $\pi$-Stacking of rhodamine B onto water-soluble polymers containing aromatic groups. Polymer 2006, 47, 6496-6500. [CrossRef]

5. Moreno-Villoslada, I.; Torres, C.; González, F.; Shibue, T.; Nishide, H. Binding of methylene blue to polyelectrolytes containing sulfonate groups. Macromol. Chem. Phys. 2009, 210, 1167-1175. [CrossRef]

6. Moreno-Villoslada, I.; Torres-Gallegos, C.s.; Araya-Hermosilla, R.; Nishide, H. Influence of the linear aromatic density on methylene blue aggregation around polyanions containing sulfonate groups. J. Phys. Chem. B 2010, 114, 4151-4158. [CrossRef] [PubMed]

7. Araya-Hermosilla, E.; Muñoz, D.; Orellana, S.; Yáñez, A.; Olea, A.F.; Oyarzun-Ampuero, F.; Moreno-Villoslada, I. Immobilization of rhodamine $6 \mathrm{G}$ in calcium alginate microcapsules based on aromatic-aromatic interactions with poly (sodium 4-styrenesulfonate). React. Funct. Polym. 2014, 81, 14-21. [CrossRef]

8. Moreno-Villoslada, I.; González, F.; Rivera, L.; Hess, S.; Rivas, B.L.; Shibue, T.; Nishide, H. Aromatic-Aromatic Interaction between 2, 3, 5-Triphenyl-2 H-tetrazolium Chloride and Poly (sodium 4-styrenesulfonate). J. Phys. Chem. B 2007, 111, 6146-6150. [CrossRef]

9. Moreno-Villoslada, I.; Soto, M.; González, F.; Montero-Silva, F.; Hess, S.; Takemura, I.; Oyaizu, K.; Nishide, H. Reduction of 2, 3 , 5-Triphenyl-2 H-tetrazolium Chloride in the Presence of Polyelectrolytes Containing 4-Styrenesulfonate Moieties. J. Phys. Chem. $B$ 2008, 112, 5350-5354. [CrossRef]

10. Moreno-Villoslada, I.; Torres, C.; González, F.; Soto, M.; Nishide, H. Stacking of 2, 3, 5-Triphenyl-2 H-tetrazolium Chloride onto Polyelectrolytes Containing 4-Styrenesulfonate Groups. J. Phys. Chem. B 2008, 112, 11244-11249. [CrossRef]

11. Flores, M.E.; Garcés-Jerez, P.; Fernández, D.; Aros-Perez, G.; González-Cabrera, D.; Álvarez, E.; Cañas, I.; Oyarzun-Ampuero, F.; Moreno-Villoslada, I. Facile Formation of Redox-Active Totally Organic Nanoparticles in Water by In Situ Reduction of Organic Precursors Stabilized through Aromatic-Aromatic Interactions by Aromatic Polyelectrolytes. Macromol. Rapid Commun. 2016, 37, 1729-1734. [CrossRef]

12. Moreno-Villoslada, I.; Oyarzún, F.; Miranda, V.; Hess, S.; Rivas, B.L. Comparison between the binding of chlorpheniramine maleate to poly (sodium 4-styrenesulfonate) and the binding to other polyelectrolytes. Polymer 2005, 46, 7240-7245. [CrossRef]

13. Moreno-Villoslada, I.; González, F.; Rivas, B.L.; Shibue, T.; Nishide, H. Tuning the pK a of the antihistaminic drug chlorpheniramine maleate by supramolecular interactions with water-soluble polymers. Polymer 2007, 48, 799-804. [CrossRef]

14. Orozco, F.; Redondo-Gómez, C.; Vega-Baudrit, J.R.; Moreno-Villoslada, I. On the comparison between diafiltration and isothermal titration calorimetry: Determination of the amount of analytes bound to water-soluble polymers. Polym. Test. 2019, 76, 443-447. [CrossRef]

15. Villamizar-Sarmiento, M.G.; Molina-Soto, E.F.; Guerrero, J.; Shibue, T.; Nishide, H.; Moreno-Villoslada, I.; Oyarzun-Ampuero, F.A. A New Methodology to Create Polymeric Nanocarriers Containing Hydrophilic Low Molecular-Weight Drugs: A Green Strategy Providing a Very High Drug Loading. Mol. Pharm. 2019, 16, 2892-2901. [CrossRef] [PubMed]

16. Villamizar-Sarmiento, M.G.; Guerrero, J.; Moreno-Villoslada, I.; Oyarzun-Ampuero, F.A. The key role of the drug self-aggregation ability to obtain optimal nanocarriers based on aromatic-aromatic drug-polymer interactions. Eur. J. Pharm. Biopharm. 2021, 166, 19-29. [CrossRef]

17. Manning, G.S. The molecular theory of polyelectrolyte solutions with applications to the electrostatic properties of polynucleotides. Q. Rev. Biophys. 1978, 11, 179-246. [CrossRef]

18. Manning, G.S. Limiting laws and counterion condensation in polyelectrolyte solutions. 8. Mixtures of counterions, species selectivity, and valence selectivity. J. Phys. Chem. 1984, 88, 6654-6661. [CrossRef]

19. Manning, G.S. Counterion condensation theory constructed from different models. Phys. A Stat. Mech. Its Appl. 1996, 231, 236-253. [CrossRef]

20. Nordmeier, E.; Dauwe, W. Studies of Polyelectrolyte Solutions I. Counterion Condensation by Poly (styrene sulfonate). Polym. J. 1991, 23, 1297-1305. [CrossRef]

21. Nordmeier, E. Advances in polyelectrolyte research: Counterion binding phenomena, dynamic processes, and the helix-coil transition of DNA. Macromol. Chem. Phys. 1995, 196, 1321-1374. [CrossRef] 
22. Flores, M.E.; Sano, N.; Araya-Hermosilla, R.; Shibue, T.; Olea, A.F.; Nishide, H.; Moreno-Villoslada, I. Self-association of 5, 10, 15, 20-tetrakis-(4-sulfonatophenyl)-porphyrin tuned by poly (decylviologen) and sulfobutylether- $\beta$-cyclodextrin. Dye. Pigment. 2015, 112, 262-273. [CrossRef]

23. Araya-Hermosilla, E.; Orellana, S.L.; Toncelli, C.; Picchioni, F.; Moreno-Villoslada, I. Novel polyketones with pendant imidazolium groups as nanodispersants of hydrophobic antibiotics. J. Appl. Polym. Sci. 2015, 132. [CrossRef]

24. Araya-Hermosilla, E.; Roscam Abbing, M.; Catalán-Toledo, J.; Oyarzun-Ampuero, F.; Pucci, A.; Raffa, P.; Picchioni, F.; MorenoVilloslada, I. Synthesis of tuneable amphiphilic-modified polyketone polymers, their complexes with 5,10,15,20-tetrakis-(4sulfonatophenyl)-porphyrin, and their role in the photooxidation of 1,3,5-triphenylformazan confined in polymeric nanoparticles. Polymer 2019, 167, 215-223. [CrossRef]

25. Fuenzalida, J.P.; Flores, M.E.; Móniz, I.s.; Feijoo, M.; Goycoolea, F.; Nishide, H.; Moreno-Villoslada, I. Immobilization of hydrophilic low molecular-weight molecules in nanoparticles of chitosan/poly (sodium 4-styrenesulfonate) assisted by aromaticaromatic interactions. J. Phys. Chem. B 2014, 118, 9782-9791. [CrossRef]

26. Coronel, A.; Catalán-Toledo, J.; Fernández-Jaramillo, H.; Godoy-Martínez, P.; Flores, M.E.; Moreno-Villoslada, I. Photodynamic action of methylene blue subjected to aromatic-aromatic interactions with poly (sodium 4-styrenesulfonate) in solution and supported in solid, highly porous alginate sponges. Dye. Pigment. 2017, 147, 455-464. [CrossRef]

27. Pino-Pinto, J.P.; Oyarzun-Ampuero, F.; Orellana, S.L.; Flores, M.E.; Nishide, H.; Moreno-Villoslada, I. Aerogels containing 5, 10, 15, 20-tetrakis-(4-sulfonatophenyl)-porphyrin with controlled state of aggregation. Dye. Pigment. 2017, 139, 193-200. [CrossRef]

28. Sanhueza, L.; Castro, J.; Urzúa, E.; Barrientos, L.; Oyarzun-Ampuero, F.; Pesenti, H.c.; Shibue, T.; Sugimura, N.; Tomita, W.; Nishide, H. Photochromic Solid Materials Based on Poly (decylviologen) Complexed with Alginate and Poly (sodium 4-styrenesulfonate). J. Phys. Chem. B 2015, 119, 13208-13217. [CrossRef]

29. Araya-Hermosilla, E.; Catalán-Toledo, J.; Muñoz-Suescun, F.; Oyarzun-Ampuero, F.; Raffa, P.; Polgar, L.M.; Picchioni, F.; MorenoVilloslada, I. Totally Organic Redox-Active pH-Sensitive Nanoparticles Stabilized by Amphiphilic Aromatic Polyketones. J. Phys. Chem. B 2018, 122, 1747-1755. [CrossRef] [PubMed]

30. Catalán-Toledo, J.; Nenen, A.; Vallejos, G.A.; Oyarzun-Ampuero, F.; Shibue, T.; Nishide, H.; Moreno-Villoslada, I. A simple and green methodology to assemble poly (4-vinylpyridine) and a sulfonated azo-dye for obtaining stable polymeric nanoparticles. Polymer 2018, 158, 289-296. [CrossRef]

31. Araya-Hermosilla, R.; Araya-Hermosilla, E.; Torres-Gallegos, C.; Alarcón-Alarcón, C.; Moreno-Villoslada, I. Sensing Cu ${ }^{2+}$ by controlling the aggregation properties of the fluorescent dye rhodamine $6 \mathrm{G}$ with the aid of polyelectrolytes bearing different linear aromatic density. React. Funct. Polym. 2013, 73, 1455-1463. [CrossRef]

32. Carrillo, J.-M.Y.; Dobrynin, A.V. Detailed Molecular Dynamics Simulations of a Model NaPSS in Water. J. Phys. Chem. B 2010, 114, 9391-9399. [CrossRef]

33. Mantha, S.; Yethiraj, A. Conformational Properties of Sodium Polystyrenesulfonate in Water: Insights from a Coarse-Grained Model with Explicit Solvent. J. Phys. Chem. B 2015, 119, 11010-11018. [CrossRef]

34. Zhang, Y.; Douglas, J.F.; Ermi, B.D.; Amis, E.J. Influence of counterion valency on the scattering properties of highly charged polyelectrolyte solutions. J. Chem. Phys. 2001, 114, 3299-3313. [CrossRef]

35. Matsuoka, H.; Schwahn, D.; Ise, N. Observation of cluster formation in polyelectrolyte solutions by small-angle neutron scattering. 1. A steep upturn of the scattering curves from solutions of sodium poly (styrenesulfonate) at scattering vectors below 0.01.ANG.-1. Macromolecules 1991, 24, 4227-4228. [CrossRef]

36. Combet, J. Polyelectrolytes and small angle scattering. EPJ Web Conf. 2018, 188, 03001. [CrossRef]

37. Ise, N.; Okubo, T.; Kunugi, S.; Matsuoka, H.; Yamamoto, K.; Ishii, Y. "Ordered" structure in dilute solutions of sodium polystyrenesulfonates as studied by small-angle x-ray scattering. J. Chem. Phys. 1984, 81, 3294-3306. [CrossRef]

38. Nishida, K.; Kaji, K.; Kanaya, T.; Shibano, T. Added Salt Effect on the Intermolecular Correlation in Flexible Polyelectrolyte Solutions: Small-Angle Scattering Study. Macromolecules 2002, 35, 4084-4089. [CrossRef]

39. Nause, R.G.; Hoagland, D.A.; Strey, H.H. Structural Evolution of Complexes of Poly (styrenesulfonate) and Cetyltrimethylammonium Chloride. Macromolecules 2008, 41, 4012-4019. [CrossRef]

40. Fares, H.M.; Ghoussoub, Y.E.; Delgado, J.D.; Fu, J.; Urban, V.S.; Schlenoff, J.B. Scattering Neutrons along the Polyelectrolyte Complex/Coacervate Continuum. Macromolecules 2018, 51, 4945-4955. [CrossRef]

41. Essafi, W.; Spiteri, M.-N.; Williams, C.; Boue, F. Hydrophobic Polyelectrolytes in Better Polar Solvent. Structure and Chain Conformation as Seen by SAXS and SANS. Macromolecules 2009, 42, 9568-9580. [CrossRef]

42. Mertens, H.D.T.; Svergun, D.I. Structural characterization of proteins and complexes using small-angle X-ray solution scattering. J. Struct. Biol. 2010, 172, 128-141. [CrossRef] [PubMed]

43. Agbabiaka, A.; Wiltfong, M.; Park, C. Small Angle X-Ray Scattering Technique for the Particle Size Distribution of Nonporous Nanoparticles. J. Nanopart. 2013, 2013, 11. [CrossRef]

44. Dobrynin, A.V.; Colby, R.H.; Rubinstein, M. Scaling Theory of Polyelectrolyte Solutions. Macromolecules 1995, $28,1859-1871$. [CrossRef]

45. Terao, K.; Morihana, N.; Ichikawa, H. Solution SAXS measurements over a wide temperature range to determine the unperturbed chain dimensions of polystyrene and a cyclic amylose derivative. Polym. J. 2014, 46, 155-159. [CrossRef]

46. Jouault, N.; Dalmas, F.; Said, S.; Di Cola, E.; Schweins, R.; Jestin, J.; Boué, F. Direct Measurement of Polymer Chain Conformation in Well-Controlled Model Nanocomposites by Combining SANS and SAXS. Macromolecules 2010, 43, 9881-9891. [CrossRef] 
47. De, R.; Das, B. Concentration, medium and salinity-induced shrinkage/expansion of Poly (sodium styrenesulfonate) in 2ethoxyethanol-Water mixed solvent media as probed by viscosimetry. J. Mol. Struct. 2020, 1199, 126992. [CrossRef]

48. Han, A.; Colby, R.H. Rheology of Entangled Polyelectrolyte Solutions. Macromolecules 2021, 54, 1375-1387. [CrossRef]

49. De, R.; Das, B. Coiling/uncoiling behaviour of sodium polystyrenesulfonate in 2-ethoxyethanol-water mixed solvent media as probed using viscometry. Polym. Int. 2014, 63, 1959-1964. [CrossRef]

50. De, R.; Ray, D.; Das, B. Influence of temperature, added electrolyte, and polymer molecular weight on the counterion-condensation phenomenon in aqueous solution of sodium polystyrenesulfonate: A scaling theory approach. RSC Adv. 2015, 5, 54890-54898. [CrossRef]

51. Bagchi, D.; Menon, R. Conformational modification of conducting polymer chains by solvents: Small-angle X-ray scattering study. Chem. Phys. Lett. 2006, 425, 114-117. [CrossRef]

52. Takano, T.; Masunaga, H.; Fujiwara, A.; Okuzaki, H.; Sasaki, T. PEDOT Nanocrystal in Highly Conductive PEDOT:PSS Polymer Films. Macromolecules 2012, 45, 3859-3865. [CrossRef]

53. Choudhury, P.K.; Bagchi, D.; Sangeeth, C.S.S.; Menon, R. Modified conformation and physical properties in conducting polymers due to varying conjugation and solvent interactions. J. Mater. Chem. 2011, 21, 1607-1614. [CrossRef]

54. Kaji, K.; Urakawa, H.; Kanaya, T.; Kitamaru, R. Phase diagram of polyelectrolyte solutions. J. Phys. 1988, 49, 993-1000. [CrossRef]

55. Nishida, K.; Kaji, K.; Kanaya, T. Improved phase diagram of polyelectrolyte solutions. J. Chem. Phys. 2001, 115, 8217-8220. [CrossRef]

56. Geckeler, K.E.; Bayer, E.; Spivakov, B.Y.; Shkinev, V.M.; Vorob'eva, G.A. Liquid-phase polymer-based retention, a new method for separation and preconcentration of elements. Anal. Chim. Acta 1986, 189, 285-292. [CrossRef]

57. Geckeler, K.E.; Volchek, K. Removal of Hazardous Substances from Water Using Ultrafiltration in Conjunction with Soluble Polymers. Environ. Sci. Technol. 1996, 30, 725-734. [CrossRef]

58. Palacio, D.A.; Rivas, B.L.; Urbano, B.F. Ultrafiltration membranes with three water-soluble polyelectrolyte copolymers to remove ciprofloxacin from aqueous systems. Chem. Eng. J. 2018, 351, 85-93. [CrossRef]

59. Stoner, M.R.; Fischer, N.; Nixon, L.; Buckel, S.; Benke, M.; Austin, F.; Randolph, T.W.; Kendrick, B.S. Protein-solute interactions affect the outcome of ultrafiltration/diafiltration operations. J. Pharm. Sci. 2004, 93, 2332-2342. [CrossRef]

60. Rivas, B.L.; Pereira, E.D.; Moreno-Villoslada, I. Water-soluble polymer-metal ion interactions. Prog. Polym. Sci. 2003, 28, 173-208. [CrossRef]

61. Moreno-Villoslada, I.; Miranda, V.; Gutiérrez, R.; Hess, S.; Muñoz, C.; Rivas, B.L. Interactions of 2, 3, 5-triphenyl-2H-tetrazolium chloride with poly (sodium 4-styrenesulfonate) studied by diafiltration and UV-vis spectroscopy. J. Membr. Sci. 2004, 244, 205-213. [CrossRef]

62. Moreno-Villoslada, I.; Miranda, V.; Jofré, M.; Chandía, P.; Villatoro, J.M.; Bulnes, J.L.; Cortés, M.; Hess, S.; Rivas, B.L. Simultaneous interactions between a low molecular-weight species and two high molecular-weight species studied by diafiltration. J. Membr. Sci. 2006, 272, 137-142. [CrossRef]

63. Orellana, S.L.; Torres-Gallegos, C.; Araya-Hermosilla, R.; Oyarzun-Ampuero, F.; Moreno-Villoslada, I. Association Efficiency of Three Ionic Forms of Oxytetracycline to Cationic and Anionic Oil-In-Water Nanoemulsions Analyzed by Diafiltration. J. Pharm. Sci. 2015, 104, 1141-1152. [CrossRef]

64. Barrat, J.-L.; Joanny, F. Theory of Polyelectrolyte Solutions. In Advances in Chemical Physics; Prigogine, I., Rice, S.A., Eds.; Wiley: Hoboken, NJ, USA, 1996; pp. 1-66.

65. Chalal, M.; Ehrburger-Dolle, F.; Morfin, I.; Bley, F.; Aguilar de Armas, M.-R.; López Donaire, M.-L.; San Roman, J.; Bölgen, N.; Pişkin, E.; Ziane, O.; et al. SAXS Investigation of the Effect of Temperature on the Multiscale Structure of a Macroporous Poly (N-isopropylacrylamide) Gel. Macromolecules 2010, 43, 2009-2017. [CrossRef]

66. Rubinstein, M.; Colby, R.H. Polymer Physics; Oxford University Press: Oxford, UK, 2003.

67. Hayashi, H.; Morita, T.; Nishikawa, K. Interpretation of correlation length by small-angle X-ray scattering experiments on fluids near critical point. Chem. Phys. Lett. 2009, 471, 249-252. [CrossRef]

68. Horkay, F.; Basser, P.J.; Hecht, A.-M.; Geissler, E. Ionic effects in semi-dilute biopolymer solutions: A small angle scattering study. J. Chem. Phys. 2018, 149, 163312. [CrossRef] [PubMed]

69. Levin, J.; Fox, J.A.; Forde, D.R. Elementary Statistics in Social Research; Pearson Allyn \& Bacon: Boston, MA, USA, 2010.

70. Nishida, K.; Urakawa, H.; Kaji, K.; Gabrys, B.; Higgins, J.S. Electrostatic persistence length of NaPSS polyelectrolytes determined by a zero average contrast SANS technique. Polymer 1997, 38, 6083-6085. [CrossRef]

71. Combet, J.; Rawiso, M.; Rochas, C.; Hoffmann, S.; Boué, F. Structure of Polyelectrolytes with Mixed Monovalent and Divalent Counterions: SAXS Measurements and Poisson-Boltzmann Analysis. Macromolecules 2011, 44, 3039-3052. [CrossRef]

72. Borsali, R.; Nguyen, H.; Pecora, R. Small-Angle Neutron Scattering and Dynamic Light Scattering from a Polyelectrolyte Solution: DNA. Macromolecules 1998, 31, 1548-1555. [CrossRef]

73. Ise, N. Ordering of Ionic Solutes in Dilute Solutions through Attraction of Similarly Charged Solutes-A Change of Paradigm in Colloid and Polymer Chemistry. Angew. Chem. Int. Ed. Engl. 1986, 25, 323-334. [CrossRef]

74. Limbach, H.J.; Holm, C. Single-Chain Properties of Polyelectrolytes in Poor Solvent. J. Phys. Chem. B 2003, 107, 8041-8055. [CrossRef]

75. Wu, D.Q.; Chu, B.; Lundberg, R.D.; MacKnight, W.J. Small-angle x-ray scattering (SAXS) studies of sulfonated polystyrene ionomers. 2. Correlation function analysis. Macromolecules 1993, 26, 1000-1007. [CrossRef] 
76. Balu, R.; Mata, J.P.; Knott, R.; Elvin, C.M.; Hill, A.J.; Choudhury, N.R.; Dutta, N.K. Effects of Crowding and Environment on the Evolution of Conformational Ensembles of the Multi-Stimuli-Responsive Intrinsically Disordered Protein, Rec1-Resilin: A Small-Angle Scattering Investigation. J. Phys. Chem. B 2016, 120, 6490-6503. [CrossRef]

77. Leisner, D.; Imae, T. Interpolyelectrolyte Complex and Coacervate Formation of Poly (glutamic acid) with a Dendrimer Studied by Light Scattering and SAXS. J. Phys. Chem. B 2003, 107, 8078-8087. [CrossRef]

78. Shrestha, L.K.; Sharma, S.C.; Sato, T.; Glatter, O.; Aramaki, K. Small-angle X-ray scattering (SAXS) study on nonionic fluorinated micelles in aqueous system. J. Colloid Interface Sci. 2007, 316, 815-824. [CrossRef]

79. Brilliantov, N.V.; Kuznetsov, D.V.; Klein, R. Chain Collapse and Counterion Condensation in Dilute Polyelectrolyte Solutions. Phys. Rev. Lett. 1998, 81, 1433-1436. [CrossRef]

80. Srivastava, A.; Qiao, W.; Ismail, K. Physicochemical Interactions of Chlorpheniramine Maleate with Sodium Deoxycholate in Aqueous Solution. J. Surfactants Deterg. 2018, 21, 879-887. [CrossRef]

81. Skerjanc, J.; Kogej, K.; Vesnaver, G. Polyelectrolyte-surfactant interactions: Enthalpy of binding of dodecyl- and cetylpyridinium cations to poly (styrenesulfonate) anion. J. Phys. Chem. 1988, 92, 6382-6385. [CrossRef]

82. Popov, A.; Zakharova, J.; Wasserman, A.; Motyakin, M.; Kasaikin, V. Macromolecular and Morphological Evolution of Poly (styrene sulfonate) Complexes with Tetradecyltrimethylammonium Bromide. J. Phys. Chem. B 2012, 116, 12332-12340. [CrossRef]

83. Sitar, S.; Goderis, B.; Hansson, P.; Kogej, K. Phase Diagram and Structures in Mixtures of Poly (styrenesulfonate anion) and Alkyltrimethylammonium Cations in Water: Significance of Specific Hydrophobic Interaction. J. Phys. Chem. B 2012, 116, 4634-4645. [CrossRef] 